\title{
Use of methadone for neuropathic pain
}

\author{
Dwight Moulin MD
}

$\mathrm{C}^{\mathrm{n}}$ hronic neuropathic pain is often considered to be a common complication of injury to the central or peripheral nervous system and the pain itself is usually assumed to be intractable. Both of these assumptions are inaccurate. For example, numbness and tingling in glove and stocking distribution are common accompaniments of longstanding diabetes mellitus, but only about $10 \%$ of patients with diabetic neuropathy consider these sensory changes to be painful (1). Anticonvulsant and antidepressant treatments provide effective analgesia in up to $50 \%$ of patients with chronic neuropathic pain (2) and there is a growing body of high-quality evidence that controlled-release opioid analgesics provide substantial pain relief in a further subset of patients (3-6). Even with polypharmacy, this still leaves perhaps 20\% to $30 \%$ of chronic neuropathic pain sufferers lacking adequate analgesia, and side effects can be problematic. In addition, central pain appears to be more refractory to opioid treatment than pain due to peripheral nerve injury (7).

In this issue of Pain Research and Management, Gagnon et al (pages 149-154) report on the efficacy of methadone in the management of chronic neuropathic pain. They performed an open-label prospective trial of methadone in 18 consecutive patients with predominantly neuropathic cancer pain. There was some selection bias favouring methadone in that only three patients were treated with adjuvant analgesics and the pretreatment mean maximal total daily opioid dose was less than $100 \mathrm{mg}$ of oral morphine equivalents. Despite this selection bias and all the inherent limitations of an open trial, the results are impressive. Mean pain intensity (Visual Analogue Scale, $0 \mathrm{~cm}$ to $10 \mathrm{~cm}$ ) dropped from a pretreatment level of $7.7 \pm 1.5$ to $1.4 \pm 1.7$ on a median stable dose of $15 \mathrm{mg}$ of methadone per day. The majority of patients reported complete resolution of mechanical allodynia and lancinating pain.

This study may provide an important avenue of treatment for intractable neuropathic pain. Methadone has unique properties as an opioid analgesic that may make it particularly suited to relieve pain due to peripheral and central nerve injury. It inhibits the reuptake of norepinephrine and serotonin in a manner similar to the properties of tricyclic antidepressants (8) and the $\mathrm{d}$-isomer has analgesic properties as an
$\mathrm{N}$-methyl-D-aspartate receptor antagonist (9). N-methyl-Daspartate antagonist activity may also reverse opioid tolerance.

This study argues for randomized, controlled trials to further delineate the efficacy and safety of methadone in malignant and nonmalignant neuropathic pain syndromes. However, that will be challenging. Given the accumulating evidence of opioid efficacy in chronic neuropathic pain, it is difficult to use a placebo control group because patients in the placebo arm may have unrelieved pain. The ideal randomized controlled trial would involve a head-to-head comparison of methadone and a conventional opioid analgesic such as morphine. The success of such a trial would rest on a comparison of methadone and morphine at equianalgesic doses; this is very problematic, especially in patients who are already opioid tolerant. For a number of reasons there is tremendous flux in the apparent equianalgesic dose ratio with repetitive dosing. Methadone is several orders of magnitude more lipid soluble than morphine and is redistributed in fat stores with slow rerelease into plasma (10). This tends to prolong the elimination half-life of methadone over time. Methadone has significant affinity for delta as well as mu opioid receptors (11). This property is one reason for the phenomenon of incomplete cross-tolerance when pain patients are switched from a conventional opioid analgesic like morphine or hydromorphone to methadone. The $\mathrm{d}$-isomer of methadone can also reverse opioid tolerance when this switch is made. All of these factors may explain the clinical observation that switching to methadone treatment in patients who have been receiving high doses of conventional opioids can provide better pain relief at doses of methadone that are $10 \%$ or less of a calculated equianalgesic dose based on single dose studies (12). Pharmacogenomics can also play a role in opioid responsiveness based on polymorphisms in mu opioid receptors (13).

Methadone may be more useful than other opioid analgesics in the management of chronic neuropathic pain, but this will be difficult to nail down. A good starting point for further studies might employ the model used by Rowbotham et al (7) in their randomized controlled trial of levorphanol for chronic neuropathic pain. They were able to show a graded analgesic response to titrated low- and high-dose levorphanol under randomized, double-blind conditions. 


\section{REFERENCES}

1. Low PA. Symptomatic treatment of painful neuropathy. JAMA 1998;280:1863-4.

2. Sindrup HJ, Jensen TS. Efficacy of pharmacological treatments of neuropathic pain: An update and effect related to mechanism of drug action. Pain 1999;83:389-400.

3. Raja SN, Haythornthwaite JA, Pappagallo M, et al. Opioids versus antidepressants in postherpetic neuralgia. Neurology 2002;59:1015-21

4. Huse E, Larbig W, Flor H, Birbaumer N. The effect of opioids on phantom limb pain and cortical reorganization. Pain 2001;90:47-55.

5. Watson CPN, Babul N. Efficacy of oxycodone in neuropathic pain: A randomized trial in postherpetic neuralgia. Neurology 1998;50:1837-41.

6. Gimbel JS, Richards P, Portenoy RK. Controlled-release oxycodone for pain in diabetic neuropathy. Neurology 2003;60:927-34.

7. Rowbotham MC, Twilling L, Davies PS, Reisner L, Taylor K, Mohr D. Oral opioid therapy for chronic peripheral and central neuropathic pain. New Eng J Med 2003;348:1223-32.
8. Codd EE, Shank RP, Schupsky JJ, Raffa BB. Serotonin and norepinephrine uptake inhibiting activity of centrally acting analgesics: Structural determinants and role in antinociception. J Pharmacol Exp Ther 1995;274:1263-70.

9. Davis AM, Inturrisi CE. d-Methadone blocks morphine tolerance and N-methyl-D-aspartate-induced hyerpalgesia. J Pharmacol Exp Ther 1999;289:1048-53.

10. Gannon C. The use of methadone in the care of the dying. Eur J Palliative Care 1997;4:152-8.

11. Pasternak GW. Multiple morphine and enkephalin receptors and the relief of pain. JAMA 1988;259:1362.

12. Ripamonti C, Groff L, Brunelli C, Polastri D, Stavrakis A, De Conno F. Switching from morphine to oral methadone in treating cancer pain: What is the equianalgesic dose ratio? Clin Oncol 1998;16:3216-21.

13. Pasternak GW. Incomplete cross-tolerance and multiple mu opioid peptide receptors. Trends Pharmacol Sci 2001;22:67-70. 


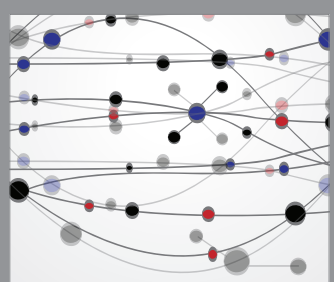

The Scientific World Journal
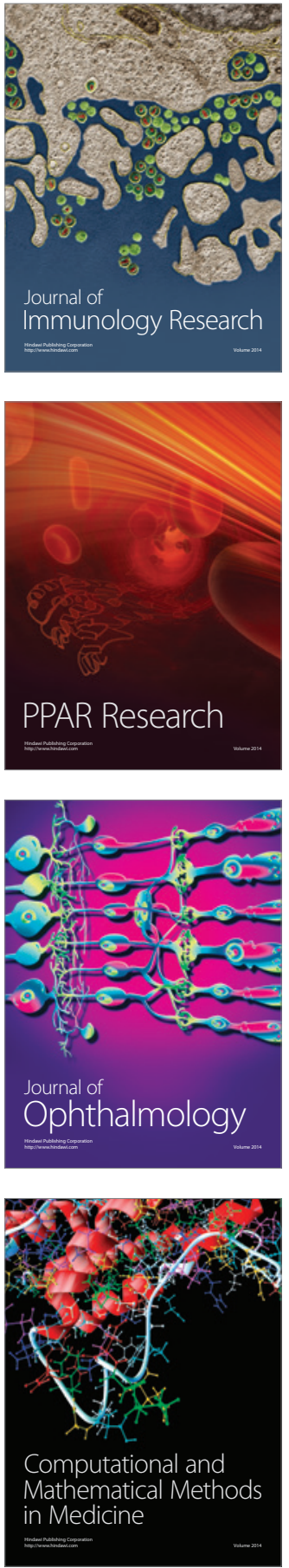

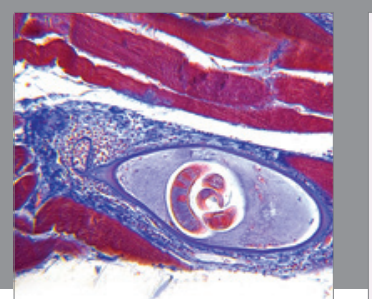

Gastroenterology Research and Practice

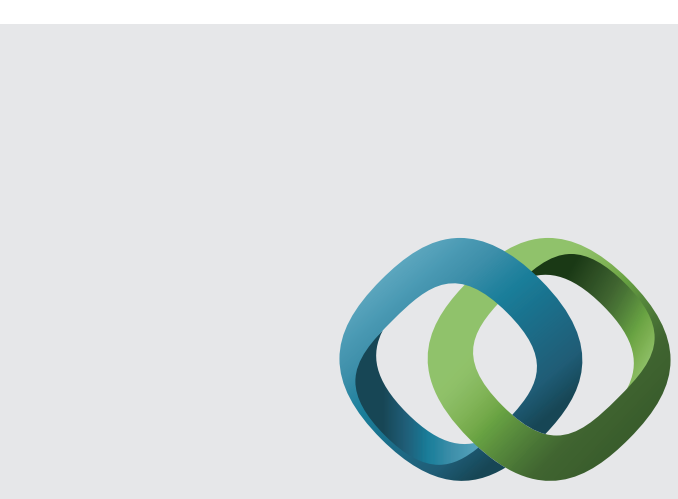

\section{Hindawi}

Submit your manuscripts at

http://www.hindawi.com
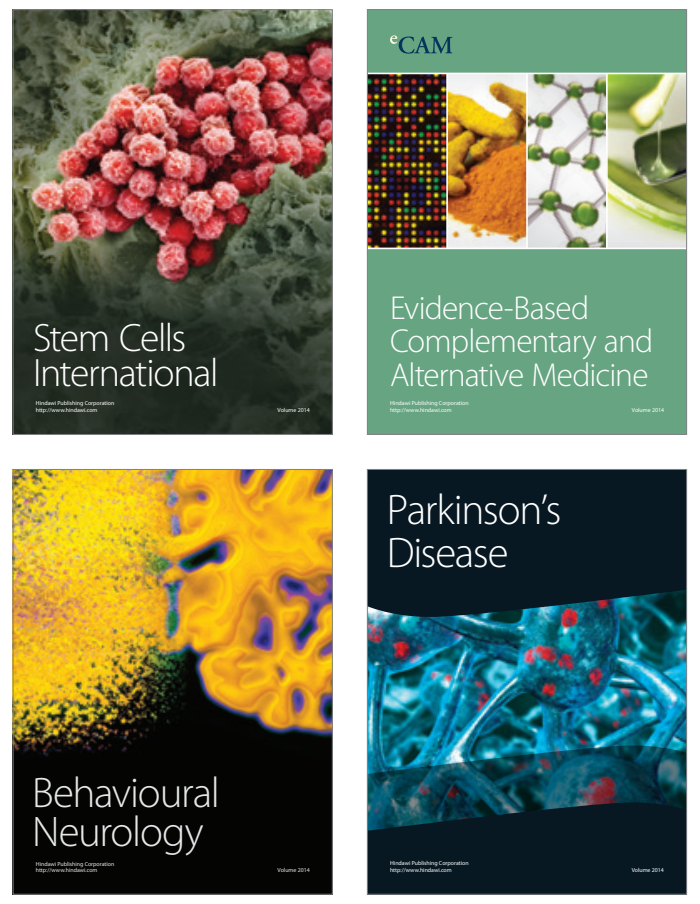
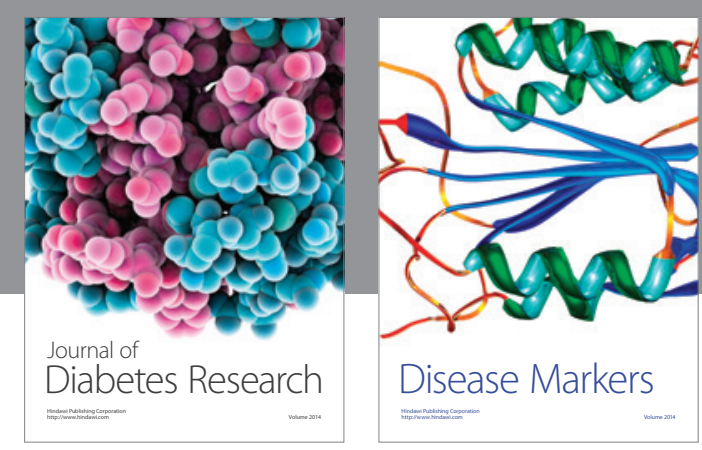

Disease Markers
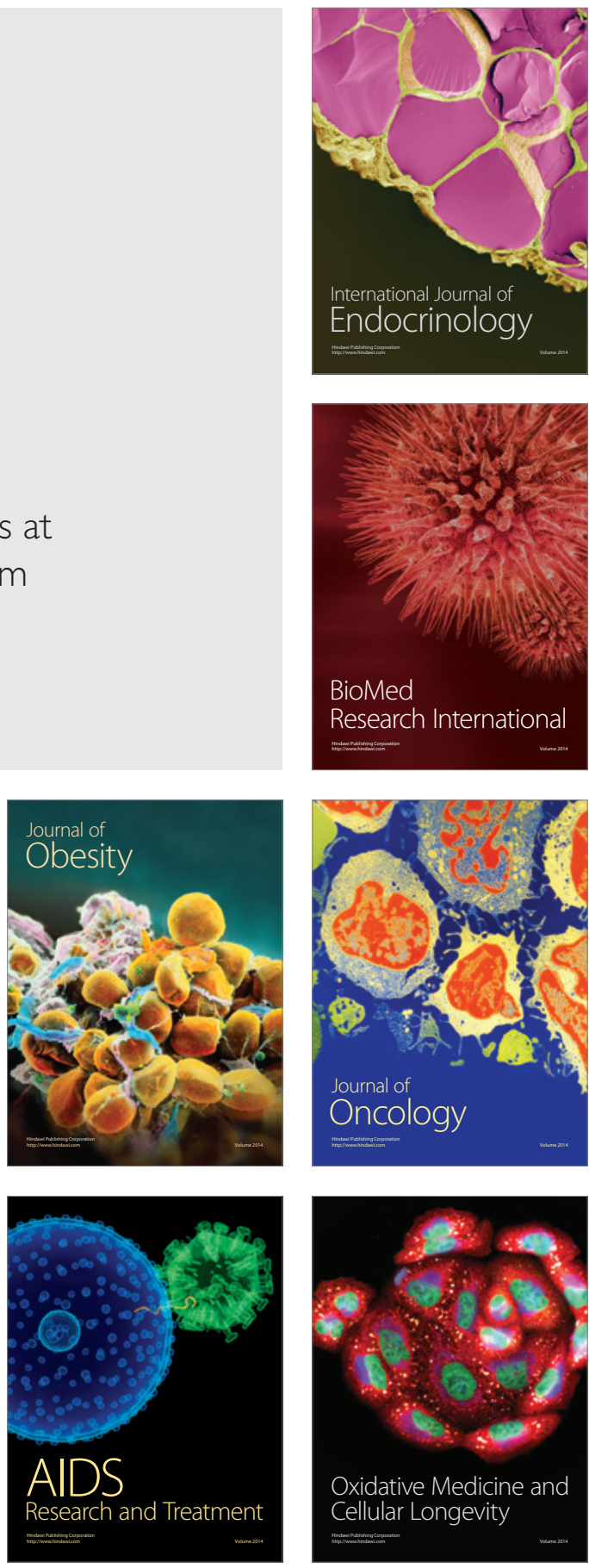